\title{
RESSIGNIFICAÇÃO DA IDENTIDADE NEGRA EM UMA ESCOLA NO DISTRITO DE SOPA, DIAMANTINA-MG
}

\author{
Andressa Carvalho da Silva \\ Paula Cristina Silva de Oliveira \\ Universidade Federal dos Vales do \\ Jequitinhonha e Mucuri
}

\section{Resumo}

Este artigo traz à tona uma reflexão acerca da ressignificação da identidade negra em uma escola no distrito de Sopa, Diamantina-MG. Constituem-se como objetivos, verificar se a lei 10.639/03, que trata do ensino da História e Cultura africana e afro-brasileira é efetivada nesta escola e proporcionar uma reflexão/valorização da beleza negra. Nilma Lino Gomes, Kabengele Munanga e Stuart Hall são citados para fundamentação do trabalho. Optando-se pela pesquisa-ação como metodologia, três etapas constituíram a intervenção. A primeira etapa consistiu em sondar dificuldades na assunção da negritude nos estudantes. A segunda, à luz da literatura, trouxe a importância do reconhecimento étnico-racial. Na terceira etapa, utilizou-se a animação "Kiriku e a Feiticeira". Ao término, autorretratos foram produzidos pelos estudantes materializando as discussões. A pesquisa denuncia a necessidade de maior atenção à temática étnico-racial nos cursos de formação de professores, para os quais essas discussões não são apenas um desafio, mas um dever.

Palavras-chave: Reconhecimento étnicoracial, identidade negra, lei 10.639/03. 


\title{
REDEFINITION OF BLACK IDENTITY IN A SCHOOL IN SOPA DISTRICT, DIAMANTINA-MG
}

\begin{abstract}
This article brings up a reflection on the redefinition of black identity in a school in Sopa district, Diamantina-MG. Constitute as goals, verify if the Law 10.639/03, which deals with the teaching of history and African Culture and african-Brazilian takes effect at this school and provide a reflection/recovery of the black beauty. Nilma Lino Gomes, Kabengele Munanga and Stuart Hall are cited for substantiation of work. Opting for action research as a methodology, three steps constituted the intervention. The first step was to probe difficulties in taking blackness in students. The second, based on the literature, brought the importance of ethnic and racial recognition. In the third step, we used the animation "Kiriku and the Witch." At the end, self-portraits were produced by students materializing discussions. The research reveals the need for greater attention to ethnic-racial theme in teacher training courses, for which those discussions are not only a challenge but a duty.
\end{abstract}

Key-words: Ethnic-racial recognition, black identity, law 10.639/03. 


\section{Contextualizando a pesquisa}

O Arraial do Tejuco, hoje Diamantina-MG, é nosso cenário, local para onde foram trazidos inúmeros escravos negros para o trabalho no garimpo. Júnia Ferreira Furtado (2006, p. 223) nos fala de um levantamento dos moradores do Arraial realizado em 1774. João da Rocha Dantas e Mendonça, intendente dos diamantes e responsável pelo levantamento, elaborou, em fevereiro de 1775, o "Mapa dos moradores do Arraial do Tejuco", considerando características como cor, profissão, estado civil, dentre outras. O referido levantamento apontava, curiosamente, para a existência de 197 mulheres forras proprietárias ou locatárias de imóveis. Destas, 110 eram africanas, 33 crioulas e 54 mestiças. Entretanto, o indicador mais intrigante do levantamento foi a ausência quase absoluta dos escravos que constituíam a maior parte da população tejucana. Furtado (2006, p.224) ainda cita um censo realizado em 1772 em que a população de escravos representava 78,5\% do total de moradores do Arraial, somando 3.610 cativos.

Quase dois séculos e meio adiante, em 2010, a estimativa do IBGE $^{1}$ (Instituto Brasileiro de Geografia e Estatística) acerca da população da atual Diamantina era de 45.880 pessoas. Dentre a população residente recenseada, 5.964 pessoas se autodeclararam pretas e outras 27.375 pessoas se autodeclararam pardas, totalizando, então, 33.339 pessoas que constituem o conjunto da população negra diamantinense $(72,66 \%$ da população residente recenseada).

Esse panorama, ainda que em linhas gerais, realça a força da presença negra desde os tempos da extração de diamantes em Diamantina. Presença que se propagou também pelos distritos da cidade. Dentre eles, o distrito de Sopa, assim nomeado em razão de uma massa argilosa constituída de lama e gravetos resultante da atividade extrativa no local, que assemelhava-se a uma sopa.

\footnotetext{
${ }^{1}$ IBGE. Censo Demográfico 2010 - Disponível em: http://www.ibge.gov.br. Olh@res, Guarulhos, v. 3, n. 1, p. 258-279. Maio, 2015.
} 
O distrito de Sopa está localizado a $12 \mathrm{~km}$ da cidade de Diamantina e tem uma população de aproximadamente 500 habitantes. No distrito só existe uma escola (pública), que tem sido palco de inúmeras situações de discriminação racial, naturalizadas no cotidiano escolar ${ }^{2}$. Diante disso, Paulo Freire nos diz que

qualquer discriminação é imoral e lutar contra ela é um dever por mais que se reconheça a força dos condicionamentos a enfrentar. A boniteza de ser gente se acha, entre outras coisas, nessa possibilidade e nesse dever de brigar. (FREIRE, 1996, p. 60).

A escola escolhida para a realização das oficinas, hoje denominada Escola Municipal de Sopa, está em funcionamento no distrito desde a década de 1930, embora na época não tivesse nome e nem respaldo legal. Em 2001, foi organizado um plebiscito onde foi votada a total absorção da instituição pela esfera municipal, já que os anos iniciais do Ensino Fundamental eram mantidos pelo Estado e os finais pelo município de Diamantina, gerando vários transtornos. Após a municipalização, a escola passou a receber estudantes da Educação Infantil até o $9^{\circ}$ ano do Ensino Fundamental. Atualmente a escola atende cerca de 146 estudantes oriundos do distrito de Sopa e de comunidades vizinhas.

A realização desse trabalho, iniciado em 2013, ano em que a lei 10.639/03 completara 10 anos, se deu em três momentos, por meio de intervenção na escola citada anteriormente. O primeiro momento foi de sondagem das dificuldades na assunção da própria negritude nos estudantes. Constatadas essas dificuldades, o segundo momento trouxe, à luz da literatura, a importância do reconhecimento étnico-racial. Para o terceiro e último momento utilizou-se a animação francesa "Kiriku e a Feiticeira", do diretor Michel Ocelot, para a (des)construção da imagem do negro.

Como metodologia utilizou-se a pesquisa-ação, a respeito da qual Rocha e Aguiar (2003) escrevem:

\footnotetext{
${ }^{2}$ Situações presenciadas durante oficinas pedagógicas realizadas pelos bolsistas do PIBID (Programa Institucional de Bolsa de Iniciação à Docência) do curso de Pedagogia da UFVJM, na escola do distrito de Sopa, Diamantina-MG. Em uma dessas oficinas, um estudante negou-se a realizar a atividade com um colega, deixando transparecer que a negação se dava pelo fato de ele ser negro. Frases como "seu cabelo é ruim, é duro", "fulano é preto que nem macaco" já foram ouvidas pelos corredores da escola. Frente a essas situações, algumas professoras preferem a omissão e, por isso, a negligência.

Olh@res, Guarulhos, v. 3, n. 1, p. 258-279. Maio, 2015.
} 
Entendida como uma ação que visa a mudanças na realidade concreta com uma participação social efetiva, a pesquisa-ação crítica está centrada no agir, através de uma metodologia exploratória, tendo seus objetivos definidos no campo de atuação pelo pesquisador e pelos participantes (ROCHA e AGUIAR, 2003, p. 65).

Ainda segundo Rocha e Aguiar (2003), as experiências com a pesquisa-ação

[...]caminham no sentido da articulação entre teoria/prática e sujeito/objeto, na medida em que o conhecimento e a ação sobre a realidade se fará na investigação das necessidades e interesses locais, na produção de formas organizativas e de uma atuação efetiva sobre essa realidade, podendo levar a transformações sociais e políticas, dando às populações excluídas uma presença ativa na História (ROCHA e AGUIAR, 2003, p. 65).

O propósito dessa pesquisa é trazer à tona uma reflexão sobre a negação da identidade negra nos educandos da referida escola, além de buscar compreender quais fatores têm contribuído para esse não-reconhecimento. Constituem-se ainda como objetivos, verificar se a lei $10.639 / 03^{3}$, que trata do ensino da cultura africana e afro-brasileira tem sido efetivada nessa escola, questionar os padrões estéticos presentes na mídia brasileira e internacional e proporcionar uma reflexão/valorização da beleza negra.

Alguns questionamentos emergiram ao longo de toda a pesquisa: a literatura e as produções audiovisuais que tratam da cultura afro-brasileira podem produzir reverberações que atinjam, de fato, os estudantes negros, promovendo uma reflexão que rompa com preconceitos? A lei 10.639/03 tem contribuído para a valorização da cultura negra no contexto escolar? Quais seriam os elementos necessários para promover a problematização dos padrões estéticos eurocêntricos e gerar uma reflexão despida de preconceitos na escola?

Nesse sentido, este trabalho buscou realizar uma pesquisa-ação junto aos estudantes do $4^{\circ}$ e $5^{\circ}$ ano do Ensino Fundamental da escola de Sopa (ainda que a última etapa tenha sido realizada também com as turmas da Educação Infantil e anos iniciais do Ensino Fundamental). $O$ grupo era

\footnotetext{
${ }^{3}$ Lei que alterou a LDBEN em 2003. Embora tenha sido modificada posteriormente em 10 de março de 2008 pela lei 11.645 , preferiu-se utilizá-la por tratar do ensino da história e cultura afro-brasileira unicamente.

Olh@res, Guarulhos, v. 3, n. 1, p. 258-279. Maio, 2015.
} 
composto por aproximadamente 25 estudantes com idade entre 10 e 14 anos.

\section{Identidade Negra: conceitos e contexto}

Se falamos em identidade negra, faz-se necessário, ainda que não seja tarefa fácil, primeiramente conceituá-la. Stuart Hall (2006), ao tratar da complexidade do conceito de identidade, pouco desenvolvido e compreendido na ciência social contemporânea, afirma que é impossível oferecer afirmações conclusivas acerca de proposições teóricas. Partindo da perspectiva do conceito de identidades culturais, o autor concebe que elas surgem a partir do pertencimento a culturas étnicas, raciais, linguísticas, religiosas, nacionais que, atualmente, encontram-se fragmentadas e em transformação.

Nilma Lino Gomes (2003, p. 171) entende a identidade negra como "uma construção social, histórica, cultural e plural. Implica a construção do olhar de um grupo étnico/racial ou de sujeitos que pertencem a um mesmo grupo étnico/racial sobre si mesmos, a partir da relação com o outro".

Desse modo, o termo identidade negra diz respeito ao ser negro e se constitui no contato/conflito com o outro, não-negro. Fruto de uma relação dialógica, a identidade negra não é um elemento que se encerra na consciência que o negro tem de si, tampouco é algo imutável; por outro lado, é flexível; assim como são as relações que estabelecemos uns com os outros.

Pensando a aquisição da identidade negra no Brasil, Munanga (2004) afirma que

Parece simples definir quem é negro no Brasil. Mas, num país que desenvolveu o desejo de branqueamento, não é fácil apresentar uma definição de quem é negro ou não. Há pessoas negras que introjetaram o ideal de branqueamento e não se 
consideram como negras. Assim, a questão da identidade do negro é um processo doloroso. Os conceitos de negro e de branco têm um fundamento etno-semântico, político e ideológico, mas não um conteúdo biológico (MUNANGA, 2004, p. 52).

A dificuldade na definição do negro no Brasil provém dos

[...]numerosos obstáculos, como a inércia e as forças das ideologias e das tradições, passadas e presentes, entre outros. Remover esses obstáculos exige a construção de novas ideologias, capazes de atingir as bases populares e convencêlas de que, sem adesão às novas propostas, serão sempre vítimas fáceis da classe dominante e de suas ideologias. (MUNANGA, 2006, p. 13)

Aqui, duas dimensões se entrecruzam: o subjetivo e o coletivo. Nesse sentido, sendo a identidade um processo sócio-histórico-cultural resultante das interações do sujeito com seu meio social e com o outro, definir-se como negro, ou não, é uma escolha inerente ao indivíduo.

Assumir-se negro demanda esforços no sentido de romper com estereótipos e ideologias enraizadas na história de nosso país desde a sua construção. Mais que um posicionamento político, autodeclarar-se negro no Brasil é também um posicionamento social. Munanga (2006, p.14) afirma que o ponto de partida para a construção de uma nova consciência, necessária para se romper com as velhas ideologias, é a questão da autodefinição, "da autoidentificação dos membros do grupo em contra-posição com a identidade dos membros do grupo "alheio", que "vai permitir o desencadeamento de um processo de construção de sua identidade ou personalidade coletiva, que serve de plataforma mobilizadora" (MUNANGA, 2006, p. 14).

Para procurar compreender as razões que levam os estudantes do distrito de Sopa a negar sua negritude, podemos analisar as palavras de Santos (2012, p.8), que nos diz que "afirmar a identidade negra faz parte de um processo de ruptura com os estigmas históricos dessa população que foi inferiorizada e subjugada diante de um ideal estético-cultural eurocêntrico, desde o Brasil colonial" e "por se tratar de um posicionamento político, identificar-se com determinado grupo étnico-racial, pressupõe aceitar as características atribuídas a ele, assim como compartilhar dessas Olh@res, Guarulhos, v. 3, n. 1, p. 258-279. Maio, 2015. 
características na sociedade" (SANTOS, 2012, p.8). Gomes fala sobre as dificuldades na construção de uma identidade negra no Brasil e deixa um questionamento que foi o ponto de partida desta pesquisa:

Construir uma identidade negra positiva em uma sociedade que, historicamente, ensina ao negro, desde muito cedo, que para ser aceito é preciso negar-se a si mesmo, é um desafio enfrentado pelos negros brasileiros. Será que, na escola, estamos atentos a essa questão? (GOMES, 2003, p. 171).

Dessa forma, a partir dos conceitos e problematizações acerca do conceito de identidades culturais, da representação da cultura negra em nossa sociedade apresentadas pelos autores citados anteriormente, persiste a seguinte questão: como efetivar a lei 10.639/03 no cotidiano escolar?

\section{Lei 10.639/03 e implicações ao contexto escolar}

Como forma de garantir que a escola se abra ao diálogo acerca da questão étnico-racial, em 9 de janeiro de 2003 foi sancionada a lei 10.639, que altera a Lei de Diretrizes e Bases da Educação Nacional 9.394/96 e estabelece a obrigatoriedade do ensino da História e Cultura Afro-Brasileira. Assim sendo, o artigo 26 da LDBEN, então alterado, preconiza que o conteúdo programático inclua

o estudo da História da África e dos Africanos, a luta dos negros no Brasil, a cultura negra brasileira e o negro na formação da sociedade nacional, resgatando a contribuição do povo negro nas áreas social, econômica e política pertinentes à História do Brasil (BRASIL, 1996).

Ressalte-se que a lei 10.639/03 foi fruto de pressões dos movimentos sociais negros e militantes engajados na luta contra o racismo por quase meio século. Em 10 de março de 2008, nova redação foi dada à LDBEN sob a lei 11.645, alterando-se novamente o artigo 26 para estabelecer a obrigatoriedade do estudo da história e cultura afro-brasileira e indígena.

Santos (2005, p.34) afirma que a obrigatoriedade do estudo da história e cultura afro-brasileira, ainda que seja condição necessária, não é condição 
suficiente para a sua implementação efetiva. Nesse sentido, Gomes (2003) entende que este:

\begin{abstract}
é mais um desafio proposto não só para os professores, mas também para os centros de formação de professores. O que sabemos sobre história e cultura afro-brasileira? O que sabemos sobre história da África? Como não reproduzir leituras e discussões estereotipadas sobre o negro e sua cultura? Que temas deveremos privilegiar dentro do vasto campo de estudo sobre a cultura afro-brasileira? São questionamentos novos que os docentes e os cursos de formação de professores começarão a fazer (GOMES, 2003, p. 180).
\end{abstract}

Dada a obrigatoriedade do ensino da História e Cultura afro-brasileira, interessa-nos buscar compreender como o mesmo se estabelece no cotidiano escolar, já que esse é um dos objetivos deste estudo.

Todas essas movimentações na sociedade brasileira evidenciaram a condição insustentável do mito da democracia racial, que aos poucos vem dando lugar a discussões menos deturpadas e, por isso, mais profundas e analíticas acerca da temática étnico-racial, principalmente na área da educação.

Por ser a escola um local privilegiado onde se estabelecem trocas, conflitos, diálogos, ela também se apresenta como um espaço de construção e ressignificação de identidade(s). O problema reside no fato de que:

\footnotetext{
A despeito e simultaneamente a isso, o sistema educacional brasileiro, da mesma forma que as demais instituições sociais, está repleto de práticas racistas, discriminatórias e preconceituosas, o que gesta, em muitos momentos, um cotidiano escolar prejudicial para o desenvolvimento emocional e cognitivo de todas as crianças e adolescentes, em especial às consideradas diferentes - com destaque para os pertencentes à população negra (CAVALLEIRO, 1998 apud CAVALLEIRO, 2005, p. 68)
}

Uma educação discriminatória e racista contribui para a evasão escolar dos estudantes negros, agravando ainda mais as desigualdades sociais, justificadas nesse caso pela baixa escolaridade, e jogando por terra o mito da igualdade entre todos, da democracia racial. 


\section{Por quê abordar as relações étnico-raciais na escola?}

A razão que impulsionou a realização desta pesquisa é angustiante. Como vimos na revisão de literatura anteriormente, algumas práticas racistas são naturalizadas no cotidiano da escola, em consonância com as vivências tidas no distrito de Sopa, Diamantina-MG. Observamos situações em que algumas professoras se omitiam ou intervinham dizendo que "todos somos iguais". A situação já insustentável, piorava à medida que percebíamos que o racismo não partia apenas dos estudantes não negros. $\mathrm{O}$ ápice da angústia provocada pela resignação se deu durante uma atividade do Estágio Supervisionado no Ensino Fundamental, exigência do curso de Pedagogia da UFVJM (Universidade Federal dos Vales do Jequitinhonha e Mucuri). $\mathrm{Na}$ atividade com a turma do $5^{\circ}$ ano do Ensino Fundamental, discutíamos o fim da escravidão, quando um estudante olhando a imagem de um escravo libertando-se das correntes que o prendiam, exclamou em alto e bom som: "Olha o macaco, tinha que ser preto mesmo". Quando perguntado sobre os motivos de ter dito aquilo, o estudante respondeu que o fez por considerar o escravo "feio e muito preto". No semestre seguinte, no decorrer do Estágio em Diversidade, as leis 10.639/2003 e 11. 645/2008, bem como pesquisas acerca desta temática foram estudados, delineando o corpo teórico da presente pesquisa.

\section{Primeiro momento - Sondagem}

Diante da necessidade de um trabalho mais profundo e cuidadoso acerca das questões étnico-raciais ${ }^{4}$ até então veladas na escola, alguns meses depois foi possível elaborar três oficinas pedagógicas, já no âmbito das ações

\footnotetext{
${ }^{4}$ Necessidade percebida durante as orientações do Estágio Supervisionado em Diversidade, componente curricular do curso de Pedagogia da UFVJM, que ofereceu as bases para a reflexão acerca do trabalho com a temática do reconhecimento étnicoracial.

Olh@res, Guarulhos, v. 3, n. 1, p. 258-279. Maio, 2015.
} 
realizadas pelo Programa Institucional de Bolsas de Iniciação à Docência PIBID, subprojeto Pedagogia da UFVJM.

A primeira oficina denominada "Sondagem" objetivou problematizar a questão da autodeclaração da cor de cada um dos estudantes do $4^{\circ}$ e $5^{\circ}$ anos do Ensino Fundamental da escola do distrito de Sopa.

Quando questionados sobre sua cor, tomados pela surpresa da pergunta, os estudantes mantiveram-se calados. Minutos depois, o silêncio foi quebrado por uma exclamação hesitada: "eu sou moreno", e logo a turma chegou ao consenso de que todos ali eram "morenos" por causa de suas origens africanas, numa tentativa de encerrar a discussão.

Em seguida, foram exibidas inúmeras imagens de personalidades da moda, atores e atrizes, cantores e cantoras, pessoas em evidência na mídia de um modo geral, para que os estudantes escolhessem quais eram os(as) mais bonitos(as). Dentre as quase 30 pessoas exibidas, nenhuma das escolhidas pelos estudantes como "mais bonitas" era negra. Esse resultado não é tão surpreendente quando consideramos que o Brasil é "um país que, apesar da miscigenação racial e cultural, ainda se apóia em um imaginário que prima por um ideal de beleza europeu e branco" (GOMES, 2006, p.5).

Questionados sobre o motivo de terem escolhido apenas pessoas brancas para ocuparem o grupo das "mais bonitas", os estudantes responderam que não se tratava de escolher apenas os brancos, já que os negros são bonitos também, mas que naquela ocasião os brancos eram mais bonitos que os negros.

Segundos depois, ouviu-se uma voz tímida ao fundo da sala denunciando que as escolhas do grupo eram racistas. Perguntamos, então, se alguém dentre os estudantes daquele grupo já havia sido vítima ou já havia presenciado alguma situação de racismo e cerca de 18 pessoas se manifestaram. Com falas atropeladas, os estudantes procuravam narrar tais situações movidos pelo sentimento de indignação. Um dos estudantes nos contou, com os olhos marejados e a voz trêmula, que já havia sido chamado Olh@res, Guarulhos, v. 3, n. 1, p. 258-279. Maio, 2015. 
de macaco por causa da cor de sua pele. Quando perguntamos qual era a sua cor ele respondeu efusivamente que não sabia, mas que ele também não era preto. Segundo Silva, Ferreira e Faria (2011):

O negro, frente a essa sociedade tomada por valores europeus, encontra-se, muitas vezes, desprovido de um parâmetro capaz de fazê-lo se reconhecer como parte dela. Dessa forma, a identidade negra pode se constituir numa identidade frustrada e aderir ao ideal do branqueamento da nação, negando, assim, a sua condição (SILVA; FERREIRA; FARIA, 2011, p. 285).

Cientes da perspectiva assinalada pelo autor, encerramos a oficina pedindo aos estudantes que pensassem sobre sua identidade étnico-racial.

\section{Utilização da literatura infanto-juvenil como veículo propulsor da discussão étnico/racial}

A opção pelo trabalho com a literatura infanto-juvenil se justifica pelo fato de que ela se apresenta como um importante elemento para a incitação do diálogo, capaz de operar mudanças no imaginário de crianças e adolescentes. Entretanto, o trato pedagógico dado à literatura deve estabelecer-se de forma cuidadosa, uma vez que:

Toda obra literária [...] transmite mensagens não apenas através do texto escrito. As imagens ilustradas também constroem enredos e cristalizam as percepções sobre aquele mundo imaginado. Se examinadas como conjunto, revelam expressões culturais de uma sociedade. A cultura informa através de seus arranjos simbólicos, valores e crenças que orientam as percepções de mundo. (LIMA, 2005, p.101)

Considerando as representações de personagens negros na literatura infantojuvenil brasileira, não é difícil encontrarmos exemplos carregados de desumanização, estereotipia, inferioridade e é nesse aspecto que se centra a necessidade do cuidado também com as imagens que ilustram tais livros. Para Souza (2001):

As imagens suscitadas tanto pelas ilustrações quanto pelas descrições e ações da personagem negra podem ser utilizadas de maneira construtiva, de modo que contribuam para a auto-estima das crianças negra, bem como para a sensibilização das não-negras (SOUZA, 2001, p. 196). 
Pensando nisso, o segundo momento de intervenção na escola procurou levantar novamente a temática do reconhecimento étnico-racial através da literatura. Utilizou-se para tanto, a leitura do livro "O cabelo de Lelê", de Valéria Belém, seguido de uma discussão sobre o mesmo.

O livro retrata a história de Lelê, menina negra que não gostava de seu cabelo volumoso e cacheado. Questionando a origem de seus cachinhos, Lelê vai em busca de um livro onde descobre suas heranças africanas. Depois de conhecer mais sobre as histórias da África, a menina passa a olhar os seus cabelos de outra forma, manipula-os e descobre sua beleza. No trecho "O negro cabelo é pura magia. Encanta o menino e a quem se avizinha" retomamos a ideia de que a identidade de um sujeito é também constituída pelo olhar do outro, pela aceitação (ou não) do outro. Ao perceber que cada cachinho do seu cabelo é uma marca de sua identidade, Lelê se alegra e fortalece sua auto-estima.

A escolha de "O cabelo de Lelê" para a composição da segunda oficina se justifica pelo fato de que a grande maioria das estudantes que compõem o grupo pesquisado, já relatou, em algum momento de nossas observações, seus dissabores com os cabelos. Assim sendo, após a leitura concomitante à exposição das imagens do livro, os estudantes foram convidados a expor suas impressões acerca da história narrada.

Como era previsto, as ilustrações do livro causaram certa estranheza aos meninos. As meninas, por sua vez, falaram das dificuldades no trato com seus cabelos também crespos, trazendo em suas falas traços que refletem os padrões de beleza eurocêntricos aos quais elas estão submetidas. Nas palavras de Gomes e Silva (2012):

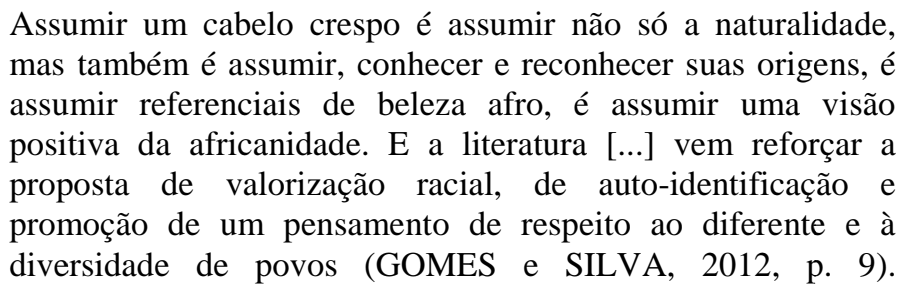

${ }^{5}$ BELÉM, Valéria. O cabelo de Lelê. 2d. São Paulo: IBEP, 2012

Olh@res, Guarulhos, v. 3, n. 1, p. 258-279. Maio, 2015. 
$\mathrm{Na}$ ocasião, promovemos um desfile da beleza afro-brasileira. Oferecemos adereços para as meninas e os meninos ornamentarem e assumirem seus cabelos, crespos ou não, numa tentativa de valorização da naturalidade e fuga dos padrões estéticos embasados no arquétipo de beleza branca.

Utilização de produção audiovisual para a (re)construção da imagem do negro

A produção francesa "Kiriku e a Feiticeira", utilizada na terceira oficina, foi inspirada por um conto africano e conta a história de Kiriku, um pequeno guerreiro que nasceu em uma aldeia subjugada pela feiticeira Karabá. Para libertar sua aldeia Kiriku decide, então, enfrentar a feiticeira, mas para isso é preciso antes encontrar o sábio que havia sido aprisionado na montanha, já que apenas ele conhece o segredo da feiticeira.

Kiriku, demasiado esperto e perspicaz, consegue encontrar o sábio e descobre, por meio dele, que Karabá é má por causa de um espinho envenenado que fora introduzido em sua espinha dorsal. Arrancando-lhe o espinho, toda a sua maldade findar-se-ia. Ajudado por sua mãe, o pequeno guerreiro vai de encontro à feiticeira e consegue arrancar o espinho de suas costas, desfazendo todos os seus feitiços. Com um beijo de Karabá, a criança dá lugar a um homem adulto e Kiriku resolve levá-la até sua aldeia. A trama se encerra com a celebração de uma grande festa.

A escolha da animação francesa utilizada como recurso metodológico na terceira e última oficina se deu em razão de que a sua narrativa oferece algumas características que fogem ao padrão vigente do uso de produções audiovisuais na escola. Como aponta Santos:

Ao invés de cenários computadorizados, o traço do desenho é delicado e fino, com cores intensas, tropicais e muito vivas, contornos nítidos; os personagens são negros e apresentados como negros, as mulheres exibem seus seios como no cotidiano da aldeia; sem o menor resíduo de puritanismo ou fetiche ocidental que os converta em

Olh@res, Guarulhos, v. 3, n. 1, p. 258-279. Maio, 2015. 
algo obsceno [...]. O ritmo da narrativa é mais lento do que o estressante ritmo alucinante das animações norte-americanas, mas tem outros atrativos mais profundos (SANTOS, 2005, p. 222).

Um dos atrativos de que nos fala Santos (2005, p. 222) é o fato de que a animação "ultrapassa em muito o maniqueísmo simplista do bem contra o mal. Não se dispõe a uma batalha empedernida, a todo custo e com todos os meios, contra a feiticeira".

A imagem do negro como herói foi recebida com certa estranheza pelos estudantes, embora também tenham demonstrado aprazimento.

Após a exibição do filme, pedimos aos estudantes (da Educação Infantil até o $5^{\circ}$ ano do Ensino Fundamental) que falassem sobre as características de Kiriku e sobre as especificidades da produção em relação aos clássicos Disney. Sobre a produção, ressaltaram que o cenário é uma aldeia africana, onde todos estão nus e isso é tido como normal e que Kiriku ajudou a feiticeira a deixar de ser má. Sobre as características de Kiriku, os estudantes apontaram que ele era pequeno, rápido, esperto, curioso e inteligente. Perguntamos sobre as características físicas do guerreiro e, em meio a várias respostas, apenas uma estudante do $2^{\circ}$ ano do Ensino Fundamental disse que Kiriku era "moreninho" e logo em seguida colocou as mãos na boca em sinal de desaprovação ao que ela própria havia falado, mesmo que tenha buscado a legitimação de sua fala ao olhar para a professora e para os demais colegas.

Percebendo o desconforto pelo qual a estudante passava mesmo sem nenhuma advertência, seus colegas se manifestaram confirmando que Kiriku realmente era "moreno". Intervimos dizendo que Kiriku e todos os outros personagens do enredo eram negros e retomamos algumas discussões da primeira e segunda oficina realizadas com os estudantes do $4^{\circ}$ e $5^{\circ}$ ano do Ensino Fundamental.

As discussões foram materializadas em um autorretrato feito por cada um dos estudantes que assistiu ao filme. Aquela estudante que se envergonhara 
de ter dito que Kiriku era moreninho disse que iria pintar sua pele no autorretrato de rosa, mas, olhando fixamente para seu braço, elaborou uma estratégia simples, embora rica em significados quando pensamos no desafio do reconhecimento étnico-racial. Pegando todos os lápis de cor de que dispunha, a estudante foi aproximando um a um do seu braço, avaliando qual dentre aquelas cores assemelhava-se mais à sua. Deteve-se por maior tempo no lápis rosa. Com um certo desapego no olhar, abandonou-o e pegou o lápis marrom. Percebendo que aquela era também a cor de sua pele, foi tomada por uma euforia desmedida e exclamou: "professora, eu também sou marrom igual ao Kiriku”. Uma de suas colegas interrompeu: "mas o Kiriku é negro e se você é da cor dele, você também é negra”. A felicidade de sua descoberta propagou-se por toda a sala.

$\mathrm{O}$ estudante do $5^{\circ}$ ano que havia narrado com comoção a experiência racista de ser chamado de macaco, mesmo ele próprio não se considerando negro, também nos surpreendeu ao colorir-se com a cor preta no autorretrato. Perguntei se aquele desenho representava sua imagem real e ele, demonstrando certo alívio, respondeu sem hesitar: "sim, esse sou eu, professora".

Os estudantes do $4^{\circ}$ e $5^{\circ}$ ano eram o grupo em que mantínhamos maiores expectativas, já que as oficinas anteriores haviam sido realizadas apenas com essas turmas. Nesse grupo, percebemos como o coletivo pode atuar sobre o subjetivo (o olhar do outro pode alterar o que penso sobre mim), uma vez que vários estudantes foram questionados pelos próprios colegas sobre o autorretrato, perceberam algumas discrepâncias e pediram outras folhas para refazerem o desenho.

Mesmo que as oficinas anteriores não tenham abrangido todas as turmas da escola, a utilização da animação parece ter alcançado os objetivos propostos, considerando que, dos 64 autorretratos produzidos, somente 2 não parecem considerar as características do autor (aos nossos olhos).

\section{CONSIDERAÇÕES FINAIS}

Olh@res, Guarulhos, v. 3, n. 1, p. 258-279. Maio, 2015. 
As experiências apresentadas e refletidas ao longo deste artigo se configuram como parte de um conjunto de experiências que vem sendo realizadas em salas de aula, escolas e redes de ensino da Educação Básica. Onze anos se passaram desde que a lei 10.639/03 foi sancionada. Sua modificação, dada pela lei 11.645/08, já completa seis anos e ambas, ainda que preconizem a obrigatoriedade do ensino da História e Cultura afrobrasileira e africana, não foram capazes de garantir sua plena efetivação (SANTOS, 2005, p. 33), embora seja difícil precisar sua eficácia, uma vez que:

O trabalho escolar não comporta neutralidades. Se, por um lado, a promulgação desta legislação se realizou em contexto de democratização social e de luta assertiva pela conquista de direitos de cidadania no país, ela se vincula a contextos escolares diversos - por suposto, não há como predizer que a recepção e a prática desta legislação ocorrerão de forma homogênea ou mesmo da maneira como prescrita ou prevista (PEREIRA, 2011, p. 149).

Embora encontremos experiências significativas que tratem da temática no ambiente escolar, em muitos casos, o trabalho com a temática étnico-racial tem sido reduzido a um ou dois dias ao longo do ano letivo ${ }^{6}$. Para Romão (2001),

\begin{abstract}
falar sobre o índio no dia 19 de abril e sobre os afro-brasileiros no dia 13 de maio pouco contribui para que as crianças se compreendam como originárias de povos que estão além da discriminação e escravidão. A visibilidade sobre estes segmentos na sala de aula tem de fazer parte de todas as rotinas escolares (ROMÃO, 2001, p.165)
\end{abstract}

A escola não deve se furtar ao diálogo das temáticas étnico-raciais,

mas, para isso, será preciso que os educadores alterem suas lógicas escolares e conteudistas, dialoguem com outras áreas, valorizem a produção cultural negra constituída em outros espaços sociais e políticos. Será preciso também ouvir e aprender as estratégias, práticas e acúmulos construídos pelo movimento negro e pelos movimentos culturais negros. $\mathrm{O}$ campo da formação de professores deverá se abrir para

\footnotetext{
${ }^{6}$ Na escola do distrito de Sopa, o ensino da História e Cultura afro-brasileira e africana ficou restrito ao dia 20 de novembro, data "celebrada" com uma feijoada para todos os estudantes e funcionários da escola.

Olh@res, Guarulhos, v. 3, n. 1, p. 258-279. Maio, 2015.
} 
dialogar com outros espaços em que negros constroem suas identidades (GOMES, 2003, p.181)

Faz-se necessário, como aponta Gomes (2003, p.181), que maior atenção seja dada aos cursos de formação de professores, para os quais as discussões étnico-raciais não se apresentam apenas como desafio, mas também como dever. Não pretendemos de maneira alguma apontar a escola como panaceia para o racismo no qual padece a sociedade brasileira, mas cabe entendê-la como parte de um processo (lento, porém de extrema importância) de ruptura de concepções, estereótipo, estigmas. Dessa forma, concordamos com Santos (2001) quando problematiza que:

\footnotetext{
Ainda que a escola sozinha não seja capaz de reverter anos de desqualificação da população negra e supervalorização da população branca, a longo prazo ela pode desempenhar um importante papel na construção de uma nova cultura, de novas relações que vão além do respeito às diferenças. Possibilitando que todas as vozes possam ecoar no espaço escolar, chegar-se-á consciência de que é na diversidade que se constrói algo novo. (SANTOS, 2001, 102).
}

Ademais, é de responsabilidade dos gestores a aquisição de materiais que sirvam de aporte didático, viabilizando discussões sobre as diferenças étnico-raciais, além do compromisso com a efetuação e valorização desses diálogos para toda a escola.

As oficinas aqui descritas representam uma tentativa de ressignificação da identidade negra dos estudantes da escola do distrito de Sopa, DiamantinaMG. Por meio da sondagem, percebemos o quão estão enraizados os padrões de beleza eurocêntricos no imaginário das crianças e adolescentes da escola. A literatura e a animação utilizadas como recursos metodológicos se apresentaram como ótimos veículos de propagação de novos valores, baseados no direito à diversidade, sem perder a ludicidade tão necessária à consolidação dos conceitos trabalhados. A produção dos autorretratos, ao término da terceira oficina, revela o êxito deste trabalho. Aos poucos, no cotidiano da escola, alguns cabelos crespos começam a ser soltos e entendidos como marca identitária e como mecanismo de resistência política. Nesse sentido, os dizeres de Santos (2001) expressam a intenção das atividades desenvolvidas. 
É tarefa da escola fazer com que a História seja contada a mais vozes, para que o futuro seja escrito a mais mãos. É necessário romper o silêncio a que foram relegados negros e índios na historiografia brasileira, para que possam construir uma imagem positiva de si mesmos (SANTOS, 2001, p.107).

Cabe destacar, conforme Hall (2006), que tempo e espaço são fatores que influenciam o conceito de identidade e a representação do sujeito. Para o autor, todo meio de representação - escrita, pintura, desenho, fotografia, simbolização através da arte ou dos sistemas de telecomunicação — deve traduzir seu objeto em dimensões espaciais e temporais. Para o autor, diferentes épocas culturais têm diferentes formas de combinar as coordenadas espaço-tempo. Nesse sentido, enfatizamos o efeito pluralizante sobre as identidades, citado pelo autor, que produz novas posições de identificação, tornando as identidades mais posicionais, mais políticas, mais plurais e diversas. 


\section{Referências bibliográficas}

BRASIL. Ministério da Educação e da Cultura. Lei de Diretrizes e Bases da Educação Nacional (Lei n ${ }^{\circ}$ 9394/96). Senado Federal. Brasília, 1996.

CAVALLEIRO, E. Discriminação racial e pluralismo na escolas públicas da cidade de São Paulo. In: Educação anti-racista: caminhos abertos pela lei Federal nº10.639/03. Brasília: Ministério da Educação, Secretaria de Educação Continuada, Alfabetização e Diversidade, 2005.

FREIRE, P. Pedagogia da autonomia: saberes necessários à prática educativa. São Paulo: Paz e Terra, 1996.

FURTADO, J. F. Quem nasce, quem chega: O mundo dos escravos no Distrito Diamantino e no Arraial do Tejuco. In: Trabalho livre, trabalho escravo: Brasil e Europa, séculos XVII e XIX. São Paulo: Annablume, p. 248, 2006.

GOMES, N. L. Alguns termos e conceitos presentes no debate sobre relações raciais no Brasil: Uma breve discussão. In: Educação anti-racista: caminhos abertos pela lei Federal nº10.639/03. Brasília: Ministério da Educação, Secretaria de Educação Continuada, Alfabetização e Diversidade, 2005.

N. L. Educação, identidade negra e formação de professores/as: um olhar sobre o corpo negro e o cabelo crespo. Educação e Pesquisa, São Paulo, v. 29, n. 1, p.167-182, 2003. Disponível em: <http://www.revistas.usp.br/ep/article/view/27905>. Acesso em: 13 out. 2014.

N. L. Sem perder a raiz: corpo e cabelo como símbolo de identidade negra. Belo Horizonte. Autentica, 2006.

GOMES, W. D. S.; SILVA, F. S. Por que ninguém passa a mão em cabelo 'ruim'? da negação a valorização da identidade negra. In: IV ENLIJE, 2012, Campina Grande. Revista Fiped. Campina Grande: Realize, 2012. 
HALL, S. A identidade cultural na pós-modernidade. DP\&A Editora, Rio de Janeiro, $11^{\mathrm{a}}$ edição, 2006, 102 páginas.

LIMA, H. P. Personagens negros: Um breve perfil da literatura infanto-juvenil. In: Superando o racismo na escola. Brasília: Ministério da Educação, Secretaria de Educação Continuada, Alfabetização e Diversidade, 2. ed., 2005.

MUNANGA, K. A difícil tarefa de definir quem é negro no Brasil. Estud. av. [online]. 2004, vol.18, n.50, pp. 51-66. ISSN 0103-4014. Disponível em: <http://www.scielo.br/pdf/ea/v18n50/a05v1850.pdf> Acesso em: 22 abr. 2015.

MUNANGA, K. Rediscutindo a mestiçagem no Brasil: identidade nacional versus identidade negra. Belo Horizonte: Autêntica, 2006.

PEREIRA, Júnia Sales. Diálogos sobre o exercício da docência: recepção das leis 10.639/03 e 11.645/08. Educação \& Realidade, Porto Alegre, v. 36, n. 1, p.147-172, 2011. Disponível em: 〈http://www.ufrgs.br/edu_realidade>. Acesso em: 22 abr. 2015.

ROCHA, M. L. e AGUIAR, K. F. Pesquisa-intervenção e a produção de novas análises. Psicologia: ciência e profissão. 2003, vol.23, n.4, pp. 64-73. Disponível em: $<$ http://www.scielo.br/scielo.php?script=sci_arttext\&pid=S141498932003000400010\&lng=en\&nrm=iso>. Acesso em: 22 set. 2014.

ROMÃO, J. O educador, a educação e a construção de uma auto-estima positiva no educando negro. In: Racismo e anti-racismo na educação: repensando nossa escola. São Paulo: Selo Negro, 2001.

SANTOS, I. A. A responsabilidade da escola na eliminação do preconceito racial: alguns caminhos. In: Racismo e anti-racismo na educação: repensando nossa escola. São Paulo: Selo Negro, 2001.

SANTOS, M. F. Ancestralidade e convivência no processo identitário: a dor do espinho e a arte da paixão entre Karabá e Kiriku. In: Educação anti-racista: caminhos abertos pela lei Federal nº10.639/03. Brasília: Ministério da Educação, Secretaria de Educação Continuada, Alfabetização e Diversidade, 2005. 
SANTOS, S. A. A Lei $\mathbf{N}^{\mathbf{0}} \mathbf{1 0 . 6 3 9 / 0 3}$ como fruto da luta anti-racista do movimento negro. In: Educação anti-racista: caminhos abertos pela lei Federal n¹0.639/03. Brasília: Ministério da Educação, Secretaria de Educação Continuada, Alfabetização e Diversidade, 2005.

SANTOS, S. K. B. M. M. O QUE É SER NEGRO NO BRASIL?: Uma reflexão sobre o processo de construção da identidade do povo brasileiro. Cadernos Imbondeiro, João Pessoa, v. $2, \quad$ n. $1, \quad$ p.1-12, 2012. Disponível em: <http://periodicos.ufpb.br/ojs/index.php/ci/article/view/14150/0>. Acesso em: 22 nov. 2014.

SILVA, J. P.; FERREIRA, R. V. J.; FARIA, J. S. A construção da identidade da criança negra: a literatura afro como possibilidade reflexiva. Ces Revista, Juiz de Fora, v. 25, p.283296, 2011. Disponível em: <http://www.cesjf.br/revistas/cesrevista/edicoes/2011/18_PEDAGOGIA_AConstrucao.pdf〉. Acesso em: 13 out. 2014.

SOUZA, A. L. Personagens negros na literatura infanto-juvenil: rompendo estereótipos In: Racismo e anti-racismo na educação: repensando nossa escola. São Paulo: Selo Negro, 2001.

Recebido para publicação em 02 de fevereiro de 2015 Aprovado em 10 de abril de 2015 